\title{
Making a Case for Local Combined Head and Power and District Heating Infrastructures within the United Kingdom Policy Landscape
}

\author{
Javier Urquizo ${ }^{1,3, *}$, Carlos Calderón ${ }^{1}$, and Philip James ${ }^{2}$ \\ ${ }^{1}$ School of Architecture Planning \& Landscape, Newcastle University, Newcastle upon Tyne, UK, NE1 7RU \\ ${ }^{2}$ School of Civil Engineering \& Geosciences, Newcastle University, Newcastle upon Tyne, UK, NE1 7RU \\ ${ }^{3}$ Escuela Superior Politécnica del Litoral, Facultad de Ingeniería en Electricidad y Computación, Campus Gustavo Galindo Km. 30.5 Vía \\ Perimetral, P.O. Box 09-01-5863, Guayaquil, Ecuador
}

\begin{abstract}
Planning energy infrastructure at the local level is the key to addressing some of the most difficult challenges in climate change and energy policy planning (i.e. fuel poverty) and to unlock the transformative potential of distributed energy technologies. The scientific field of urban energy and carbon modelling is becoming a fundamental instrument to estimate an energy and carbon baseline at a point in time and to quantify the impact that policy-driven technological interventions that could have on the overall carbon footprint of a city. This capability enables an evidence-based approach in which the economic case towards a low-carbon economy can be made. Transformative local distributed energy technologies such as CHP or district heating have a strong spatial component due to a need to identify synergies with adjacent properties or heating loads. Currently available domestic building energy models often do not take into account spatial information. Accessing geo-referenced data for energy modelling can also be particularly useful as validated outputs (i.e. heating and electricity loads, energy profiles) can be mapped using spatial modelling techniques that help to easily identify high and low energy consumption areas and potential synergies in local energy infrastructure planning. In Newcastle upon Tyne UK, the council is exploring the opportunities for the installation of renewable heat technologies on their own stock as a matter of urgency. Identification of potential sites and feasibility for technical and financial applicability within the UK policies will be addressed by this paper.
\end{abstract}

\section{The legislation and regulation affecting building's sustainable design}

The development of a low carbon district heating and cooling network is the largest single element identified within Newcastle City Council [1] energy master-plan and is the project that is likely to have the greatest impact in delivering low carbon energy to the city [2]. This paper first reviews the sustainability legislation and regulations influencing UK building design and construction. In the $\mathrm{UK}$, regulated $\mathrm{CO}_{2}$ emissions are those building emissions that are regulated under Part $\mathrm{L}$ of the Building Regulations [3]. Regulated emissions include those associated with the building fabric and fixed services; unregulated emissions include those from the use of cooking, appliances, and equipment.

The UK government has set a legally binding target to reduce national greenhouse gas emissions by at least $80 \%$ by 2050 through the Climate Change Act [4]. The Act also introduced a system of carbon budgets which provide limits on the amount of emissions produced in successive five-year periods, starting in 2008. The CCC [5] provides the tools for doing that providing actions through the carbon budgets ${ }^{a}$ to make sure that the progress is in a steady and efficient form toward the year 2050. The first three carbon budgets require emissions to be reduced by at least $34 \%$ below base year levels in 2020 , the fourth a reduction of $50 \%$ by 2027 . The carbon budgets also require that the government of the date provides legislation, proposals and actions that are consistent with the carbon budgets as they pass one after another. However, even though there is scientific evidence that the climate change exists, it should be noted that in the wider debate there is uncertainty in both how large it is, what the cost, on where is going to impact and the appropriate response to mitigate its effect. There are metrics, probably the most popular are around temperature change (used by the CCC) to monitor and keep track of the climate change.

Progress has been made in the building sector. Despite the increase in the number of households from 19 million to 27 million and population from 56 million to

\footnotetext{
a The CCC provides recommendation about those carbon budgets and to report progress about those carbon budgets.

${ }^{\mathrm{b}}$ Other might use sea level rise change, storms, floods, acidity and others.
} 
64 million in the 1970 to 2012 year period; the average energy use per household has reduced from $22,600 \mathrm{kWh}$ to $18,600 \mathrm{kWh}$ and the average $\mathrm{CO}_{2}$ per household from 9.6 tonnes to 5.0 tonnes in the same period [6]. However, the reduction in electricity used in peak periods and how much of this could be switched to periods of lower electrical demand [7] is still needed to model and understanding.

\subsection{Zero carbon targets}

The UK government supports a hierarchical approach to meeting a zero carbon standard for buildings [8]. This hierarchy considers first energy efficiency parameters (e.g. high levels of insulation, passive use of solar energy and a low level of air leakage through unsealed joints, passive preheating of fresh air and mechanical ventilation with heat recovery); and second, carbon mitigation onsite (or near-site), and offsite low and zero carbon energy ${ }^{c}$ (LCZ). In a building, a greener future policy [9] considers for a LCZ any type of technology (approved by the Standard Assessment Procedure SAP) that has a physical connection to the development, even if the technology is partly (or wholly) located away from the development site itself, as is often the case for district heating/CHP; and finally, a buy-out fund whose proceeds would be used to invest in low and zero carbon energy (e.g. offsite renewable electricity generation) contributing to the home that is tackling emissions, and additionally exporting low carbon or renewable heat to neighbouring developments or investing in LZC community heating.

In other to verify that the home is energy efficient, there are two known standards the Passivhaus Trust [10] standard, and nationally the Energy Saving Trust (EST) publishes standards which can satisfy the higher levels of the Code for Sustainable Homes [11].

\subsection{Part $L$ of the building regulations}

The HM Government [12] and the HM Government [13] approved Documents L (Conservation of fuel and power) provide practical guidance on ways of complying with the energy efficiency requirements of the Building Regulations. Approved Document L implements the requirements of the Energy Performance of Buildings Directive (EPBD) at a national level and has a key role to play in defining suitable intermediate steps on the trajectory towards zero carbon buildings. Compliance with Building Regulations is a legal requirement that applies to most new buildings and many alterations of existing buildings in England [14]. The 2013 edition of Approved Documents L1A, Conservation of fuel and power in new dwellings and L2A: Conservation of fuel and power in new buildings other than dwellings; and the 2010 Approved Documents L1B: Conservation of fuel and power in existing dwellings and L2B Conservation of

\footnotetext{
${ }^{\mathrm{c}}$ LZC are technologies directly incorporated into the fabric of the home (e.g. roof-mounted solar panels), therefore are included in the carbon compliance calculation of the home and therefore included into the SAP calculation methodology.
}

fuel and power in new buildings other than dwellings are the current editions for use in England. L1A and L2A came into effect on 6 April 2014. Part L is currently updated on a three-year cycle.

Part L (England) includes the following requirements: maximum allowable calculated $\mathrm{CO}_{2}$ emissions rate; maximum allowable U-values for planar elements; Maximum allowable airtightness; guidance to reduce non-repeating thermal bridging; checks to ensure control of solar gain and overheating. In addition, Part L1A has introduced mandatory Fabric Energy Efficiency Standards (FEES) alongside the existing $\mathrm{CO}_{2}$ emissions targets.

In the energy and $\mathrm{CO}_{2}$ requirement, the Part $\mathrm{L}$ [15] requires that the calculated rate of $\mathrm{CO}_{2}$ emissions from the dwelling - the Dwelling $\mathrm{CO}_{2}$ Emission Rate (DER) must not be greater than the Target $\mathrm{CO}_{2}$ Emission Rate (TER) and the calculated Dwelling Fabric Energy Efficiency (DFEE) rate must not be greater than the Target Fabric Energy Efficiency (TFEE). The calculated DER, calculated using the BRE [16], is based on the annual energy requirements for space heating, water heating, and lighting, less the emissions saved by renewable energy generation technologies.

\subsection{Energy Performance Certificates (EPCs)}

The EPC-SAP [17] gives the theoretical (predicted) energy efficiency performance (the Asset Rating) of the building on a linear scale from $A$ to $G$, where $A$ is the most energy efficient, carbon neutral building. Each EPC is provided with an accompanying Recommendation Report [18] providing options that could potentially improve the energy efficiency of the building and thereby the building's individual EPC rating. The A to G scale is a linear scale based on two key points defined as follows the zero point on the scale is defined as the performance of the building that has zero net annual $\mathrm{CO}_{2}$ emissions associated with the use of the fixed building services as defined in the Building Regulations.

The next two sections deal with the main policies from the European Union (EU) and the code for sustainable homes $(\mathrm{CSH})$. The Code for Sustainable Homes is the domestic version of Building Research Establishment Environmental Assessment Method (BREEAM) [19] and provides an environmental assessment methodology for certifying the performance of new homes in England. Since 2008 CSH [11] has been mandatory for all new homes to be rated (not assessed) against the Code. Buildings that are not assessed under the Code are awarded a 'nil-rated' certificate. The CSH assigns one or more performance requirements (assessment criteria) to all of the environmental issues. Mandatory minimum performance standards are set for the dwelling emission rate (DER) and indoor water use (IWU) fabric energy efficiency (FEE) and lifetime homes (LH).

\subsection{Energy directives}


The EU directives lay down certain end results that must be achieved in every Member State. National authorities (e.g. UK) have to adapt their laws to meet these goals but are free to decide how to do so. Directives may concern one or more Member States, or all of them [20]. The EU directives that are related to this paper are (i) energy performance of buildings, (ii) energy efficiency, (iii) renewable energy, (iv) cogeneration - combined heat and power, and (v) the third package.

i. Energy performance of buildings (EPDB). EPBD Directive [21] promotes

The improvement of the energy performance of buildings within the Union, taking into account outdoor climatic and local conditions, as well as indoor climate requirements and costeffectiveness

The EPDB has set minimum requirements to the energy performance of buildings setting national plants for increasing the number of nearly zero-energy buildings and the certification of buildings through the Energy Performance Certificates (EPC). The Code for Sustainable Homes (CSH) sets standards of sustainability which are mandatory in the EPDB, therefore, limiting the environmental impact of the housing sector and most important sets a mechanism by which the construction sector can demonstrate the improvement in the energy performance of a building. The EPC for new homes was introduced in 2008 under the EPBD.

Building regulations for new homes in England do not specify that a particular efficiency measure needs to be installed, but do set out minimum standards of performance for heat loss from walls and roofs from which it is possible to estimate the necessary level of cavity wall or loft insulation.

ii. Energy Efficiency. The Directive [22] establishes a common framework of measures for the "promotion of energy efficiency within the Union in order to ensure the achievement of the Union's $202020 \%$ headline target on energy efficiency and to further energy efficiency improvements beyond that date."

All countries are required to use energy more efficiently at all stages of the energy chain -from the transformation of energy and its distribution to its final consumption. The Directive will establish an indicative national energy efficiency targets for 2020 .

iii. Renewable energy. The directive [23] requires in article 4 that "Member States submit national renewable energy Action Plans. These plans, to be prepared in accordance with the template published by the European Commission (EC), provide detailed roadmaps of how each Member State expects to reach its legally binding 2020 target for the share of renewable energy in their final energy consumption".

iv. Cogeneration - Combined Heat and Power. The purpose of the cogeneration Directive is to "increase energy efficiency and improve security of supply by creating a framework for promotion and development of high efficiency cogeneration of heat and power based on useful heat demand and primary energy savings" in the internal energy market. As such, it covers a number of definitional issues, as well as calculation methodologies and several key areas.

v. Third energy package. The European Union's Third Energy Package [24] is a "legislative package for an internal gas and electricity market in the European Union. Its purpose is to further open up the gas and electricity markets in the European Union."

Core elements of the third package include "ownership unbundling, which stipulates the separation of companies: generation and sale operations from their transmission networks, and the establishment of a National regulatory authority (NRA) for each Member State, and the Agency for the Cooperation of Energy Regulators which provides a forum for NRAs to work together."

\subsection{Code for sustainable homes in England}

The CSH [25] was introduced in 2007 as a voluntary national standard to improve the overall sustainability of new dwellings. Later in 2010, the Part L 2010 of the Building Regulations required that all new dwellings have a DER that is a 25 percent improvement on the Part L 2006 standard (equivalent to a mandatory requirement of Code Level 3). The Code measures the "sustainability of a home against nine design categories, rating the 'whole home' as a complete package." The design categories are energy and $\mathrm{CO}_{2}$ Emissions; water; materials; surface water run-off; waste; pollution; health and wellbeing and management and ecology. A home can achieve a sustainability rating from "one to six stars depending on the extent to which it has achieved CHS standards." The 'one star' is the entry level "above the level of the Building Regulations"; and 'six stars' is the highest level "reflecting exemplary development in sustainability terms". A significant fraction of the costs of building to CHS standards are related to the energy solutions adopted in order to meet the mandatory DER under the Energy and $\mathrm{CO}_{2}$ category e.g. $\mathrm{CSH}$ level 3 requirements involves measures in the building fabric in combination with a solar thermal system or small PV array, whereas level 4 dwelling involves further measures in the in combination with a PV array. Levels 5 and 6 require further low to zero carbon technologies like heat pumps, biomass boilers and photovoltaic, or community scale like gas combined heat and power (CHP), biomass boilers and biomass combined heat and power.

\section{UK policy schemes carbon pricing, low carbon energy, energy efficiency and carbon pricing}

The current energy policy of the United Kingdom is led by the DECC and is set out in the Energy White Paper of May 2007 [26] and Low Carbon Transition Plan of July 2009 [27], building on previous work including the 2003 Energy White Paper [28] and the Energy Review Report in 2006 [29].

The 2007 energy white paper address the UK long term energy challenges and to deliver four key policy goals: (i) to put the UK on a path to cut carbon dioxide 
emissions by some $60 \%$ by about 2050, with real progress by 2020; (ii) to maintain reliable energy supplies; (iii) to promote competitive markets in the UK (proposing reforms of its electricity market, including measures such as contracts for difference for generators and a capacity market to ensure security of supply); and (iv) to ensure that every home is adequately and affordably heated.

The 2008 Energy Bill [30] updates the legislative framework in the UK to reflect their current policy towards the energy market and the challenges faced on climate change and security of supply. The key elements of the bill are address nuclear energy, carbon capture and storage, renewables, and offshore gas and oil.

The Energy Act 2011 [31] included provisions to ensure that landlords install cost-effective measures under the Green Deal from 1 April 2016, but private renters may find it difficult to take advantage of the policy before this date. Furthermore, landlords will not be able to refuse tenant's requests for measures to be installed with Green Deal financing after 2016, and where after 2018 landlords will no longer be able to rent low-efficiency properties unless all available Green Deal measures have been installed. Sections 2.1 through 2.4 outline the main policies that affect energy use by households at different stages of the energy production and consumption process.

\subsection{Policies on reducing emissions trough carbon pricing}

The following are the main UK policies through carbon pricing.

i. EU Emission Trading System (EU ETS). The EU ETS is a cap-and-trade scheme for direct emissions from energy-intensive facilities (traded sectors). The aim of the scheme is to reduce emissions in a costeffective manner, allowing companies to trade emission allowances and thereby determine how and where they reduce emissions.

ii. The Carbon Price Floor (CPF). The CPF is a minimum target price (implemented through a tax, the Carbon Price Support Rate (CPSR)) on fuels used for power generation in the UK, and is designed to 'top up' the EU ETS carbon price. It is based on the carbon content of the fuels, and is aimed at providing an incentive to invest in low-carbon power generation by creating support and certainty for the carbon price in the UK's electricity generation sector.

iii. Climate Change Levy (CCL). The CCL is a tax on energy used by industry and the public sector designed to incentivise energy efficiency and emission reductions by increasing the effective price of energy.

iv. Climate Change Agreement (CCA). The CCAs are voluntary agreements between certain energy intensive users and the government. They allow eligible industries to claim a discount on the Climate Change Levy (CCL), provided they meet targets for improving their energy efficiency or reducing their carbon emissions. v. Carbon Reduction Commitment Energy Efficiency Scheme (CRC). The CRC requires participants to monitor and report their energy consumption, and buy allowances equal to their $\mathrm{CO}_{2}$ emissions. The aim of the scheme is to encourage energy efficiency across large public and private organisations that are not already covered by the EU Emission Trading System (EU ETS) and Climate Change Agreements (CCA).

vi. Emission Performance Standards (EPS). The goal of the EPS is to limit $\mathrm{CO}_{2}$ emissions by setting mandatory emission standards for new fossil fuel power stations.

\subsection{Policies on reducing emissions through support for low carbon energy}

The following are the main UK policies for low carbon energy.

i. Renewable Obligations (RO). The Renewable Obligation (RO) is a mechanism for incentivising large-scale renewable electricity generation in the UK by requiring electricity suppliers to source a specified proportion of the electricity they provide to customers from renewable sources.

ii. Feed-in Tariffs with Contracts for Difference (CfD FITs or CfDs). The CfD FITs are long-term contracts to provide developers of eligible low-carbon generation, including nuclear, renewables and Carbon Capture and Store (CCS), with a stable revenue stream, enabling investment in low carbon energy.

iii. Small-scale Feed-in Tariffs (FITs). In 2010, the government introduced a system of feed-in tariffs (FITs) to incentivise small scale, low carbon electricity generation by providing 'clean energy cashback' for householders, communities, and businesses. These FITs work alongside the Renewables Obligation, which will remain the primary mechanism to incentivise the deployment of large-scale renewable electricity generation and the Renewable Heat Incentive (RHI) which will incentivise generation of heat from renewable sources at all scales.

iv. Renewable Heat Incentive (RHI). The aim of the RHI is to provide financial incentives to increase the generation of renewably sourced heat.

v. Capacity Mechanism. A capacity mechanism would make payments to generators for the availability of capacity (rather than for the electricity they produce) to provide sufficient incentives for investment in new capacity. The aim is to provide an insurance policy to reduce the likelihood of future blackouts and to ensure reliable electricity supply to consumers.

\subsection{Policies on improving energy efficiency}

The following are the main UK policies for energy efficiency.

i. Carbon Emission Reduction Target (CERT). The CERT aimed to reduce carbon emissions from the UK residential sector by placing an obligation on large 
energy suppliers to improve energy efficiency in the existing housing stock.

ii. Community Energy Saving Programme (CESP). The CESP aimed to work alongside CERT in order to reduce carbon emissions from the UK residential stock and focused in particular on achieving these savings in areas of low income.

iii. Energy Company Obligation (ECO). ECO aims to improve the energy efficiency of the domestic housing stock through the provision of insulation and efficiency measures for poor households or those in hard-to-treat properties.

iv. Green Deal (GD). The Green Deal aims to improve the energy efficiency of the UK building stock. It offers efficiency and insulation improvements at no upfront charge, with the cost met through loans repaid through electricity bills.

v. Products Policy (PP). The 'Products Policy' is an umbrella term for policies expected to affect the efficiency of energy-using and energy-related products. A significant part of the policy is the UK implementation of EU 'Ecodesign' Directives aimed at improving the efficiency of electrical appliances and other energy-related products through minimum energy standards. The wider Products Policy also covers mandatory energy labelling of products, supplier obligations to encourage energy efficiency, building regulations, etc.

\subsection{Policies on support of energy bills}

The following are the main UK policies for energy bills.

i. Warm Home Discount Scheme (WHDS). The WHDS aims to reduce the incidence of fuel poverty by giving electricity bill rebates to low income and vulnerable households.

ii. Winter Fuel Payment (WFP). The WFP is aimed at supporting energy costs for older people through annual tax-free payments made in winter months.

iii. Cold Weather Payment (CWP). CWPs aims to support vulnerable households in meeting unexpected increases in energy costs, by providing cash transfers following periods of extremely cold weather.

iv. Value Added Tax (VAT) on energy use. The VAT is the main consumption tax in the UK and is largely designed to raise revenue. The standard rate is $20 \%$ but domestic energy pays a reduced rate of $5 \%$.

\section{Energy efficiency schemes}

This section cover policies for energy efficiency, these policies are designed to support improvements to energy efficiency in four schemes: directs grants, long-term financial incentives, schemes to provide financing and obligations.

i. Direct grants. These are in the form of direct grants to low income and vulnerable households; previous was in the Warm Front (WF). WF was funded through general taxation (ran from 2000 to January 2013). Owner occupied and private renters are eligible for WF, initially, households that were both poor and considered vulnerable (i.e. dependent children, someone over 60 or a disabled person), by 2011 additional efficiency criteria were SAP score in excess of 55 were ineligible. In the WF scheme, 2.3 million households received assistance. The eligibility was $2 \%$ in the richest decile and one-third of households in the poorest income deciles.

ii. The long-term financial incentives. These are used to generate energy from renewable sources on a small scale (up to $5 \mathrm{MW}$ ). Currently under this scheme is the Feed-in tariff (FIT) (since 2010). Microgeneration receives a 'generation' payment for each $\mathrm{kWh}$ of energy produced. The tariff varies according to technology, size, and date of installation. Payments are guaranteed for twenty years and updated in the line with the Retail Prices Index (RPI) inflation. Further export payments are fixed per-kWh basis for exporting this energy to the national grid.

iii. The schemes for providing financing pay for energy efficiency and heating measures. Currently, the Green Deal (GD) operates since January 2013. The financing is following an assessment of the property by a qualified adviser. The granted loan pays for the up-front installation costs of measures that are deemed to be cost effective on measures that meet the 'golden rule ${ }^{\mathrm{d}}$; ; repayments (with interests) is through future energy bills. One interesting aspect of GD is that the obligations are attached to the property rather to the owner or the tenant.

iv. Obligations on energy suppliers. These are obligations on energy suppliers paid through higher energy bills. Previous schemas were the Carbon Emissions Reduction Target (CERT) (ran from April 2008 to December 2012) and the Community Energy Saving Programme (CESP) (ran from 2009 until December 2012). The current schema is the Energy Company Obligations (ECO) (run from 2013 until March 2015).

CERT aim was to save an equivalent of 293 million tonnes of $\mathrm{CO}_{2}$ total, also $10 \%$ at the top of the distribution. ${ }^{\mathrm{e}}$ CERT has two specific priority groups ( $40 \%$ of the emission reduction must be achieved in this group) householders over 70 or the householder being in receipt of any of the major means-tested or disability benefits, or in some cases tax credits. Since 2010 included low-income pensioners and lowincome people with young children or disabilities.

CESP aim was to save 19.25 million of tonnes of $\mathrm{CO}_{2}$ total, eligible are the poorest $10 \%$ of the LLSOA in England defined by the income index in the 2007 Index of Multiple Deprivation (IMD). CESP takes the 'whole house' approach, installing a number of measures including insulation, heating systems upgrades, energy efficiency advise and microgeneration technologies at once. CESP includes also electricity generators.

\footnotetext{
${ }^{\mathrm{d}}$ The amount repaid through the bill in the first year must be no more than the expected bill savings achieved by the installed measures.

${ }^{\mathrm{e}}$ The richest emit twice that of the poorest $10 \%$ of households in terms of household energy consumption.
} 
The ECO has, in turn, three schemes: the home heating cost reduction obligations (HHCRO), the carbon saving community obligation ( $\mathrm{CSCO}$ ), and the carbon saving obligation (CSO).

The HHCRO schema aims is to improve the energy efficiency for a 'warm affordability group' (in receipt of a child tax credit, working tax credit, ESA $^{\mathrm{f}}$ /income-based $\mathrm{JSA}^{\mathrm{g}}$ or income support). This schema is for properties in private accommodation (owned or rented) and also have dependent children, disabled or older household members. DECC estimation is to have at the end of the program 45,000 cavity wall insulations, 90,000 loft insulations, and 260,000 heating systems.

The CSCO aim is to save a minimum amount of $\mathrm{CO}_{2}$ in areas of low income (defined as the most deprived $15 \%$ of small areas in England); the further obligation is at least $15 \%$ of savings to people in the warmth affordability group in those areas. DECC estimation is to have at the end of the program savings of $6.8 \mathrm{MtCO}_{2}$ equivalents to 39,100 solid wall, 142,200 cavity walls, 29,000 loft, and 39,300 combined loft and cavity wall insulations.

The CSO aim is to save a minimum amount of $\mathrm{CO}_{2}$ in measures that would not qualify for the Green Deal such as solid wall insulation, cavity wall insulation in hard-to-treat homes and connexions to district heating systems. DECC estimation is to have at the end of the program 107,500 solid wall, 256,300 cavity walls and 116,800 combined cavity and loft insulation.

\subsection{Policies that impact fuel poverty}

The following are the main policies that impact the fuel poverty in UK.

i. Green Deal and ECO. Department of Energy and Climate Change estimate [32] that Green Deal and ECO combined are expected to reduce fuel poverty by 125,000 to 250,000 households from 2023 (the point at which ECO costs are no longer recouped through energy bills).

ii. Carbon Price Floor (CPF). The government estimates that the introduction of the $\mathrm{CPF}$ is expected to increase fuel poverty by $30,000-60,000$ households per year in 2013 [33].

\footnotetext{
${ }^{\mathrm{f}}$ Employment and Support Allowance

g Jobseeker's Allowance
}

iii. Warm Home Discount Scheme (WHDS). Department of Energy and Climate Change [34] estimated that the scheme would reduce fuel poverty by around 58,000 households in 2014-5.

\section{Energy efficiency policies in the residential sector}

This section explains the energy-efficiency policies in the residential sector using a Concept Map. The Concept Map (CM) is proposed as a human-friendly knowledgerepresentation of information and is a tool especially defined for application in the learning process. It is easy to create, and flexible and intuitive for people to understand [35-37].

Policies that improve thermal efficiency in lowincome households are often the most cost-effective way of reducing energy costs. The UK government has made a significant improvement in household energy efficiency through expenditure programmes (such as Warm Front and the Decent Homes Programme), and energy supplier obligations (such as the Carbon Emissions Reduction Target and the Community Energy Saving Programme). This has also been achieved through regulations - for example, through the improvement in the efficiency of appliances that has been led by the Department for the Environment, Food and Rural Affairs (Defra) or through the improvement in condensing boilers that has resulted from Department for Communities and Local Government (DCLG) policies on building regulations.

From 2013 the Green Deal is the key policy supporting households to lower energy costs through the installation of energy efficiency measures. The Green Deal is designed to help households pay for energy efficiency improvements through the savings that they make on their bill. Alongside the Green Deal, the Energy Company Obligation (ECO) requires energy suppliers to support the delivery of measures in 'hard to treat' households that do not meet the 'Golden Rule' and amongst low-income households.

\subsection{Fuel poverty modelling}

The key elements in determining whether a household is fuel poor or not are: (i) income, see Figure 1; (ii) fuel prices; and (iii) fuel consumption, see Figure 2. This research will compute the full income in each household.

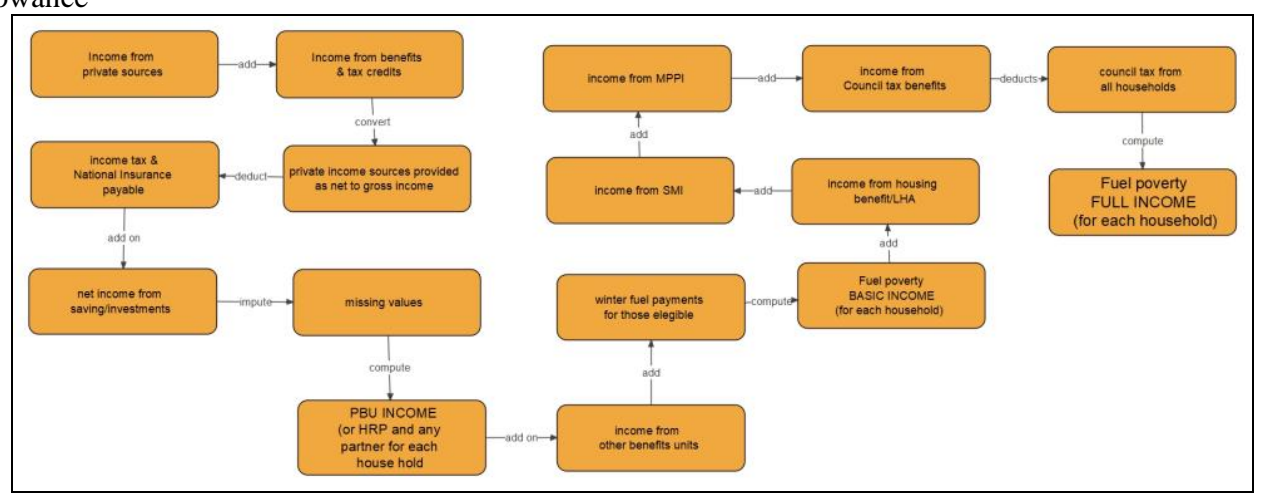

Fig. 1. Full incomes (defined for fuel poverty) for each household 


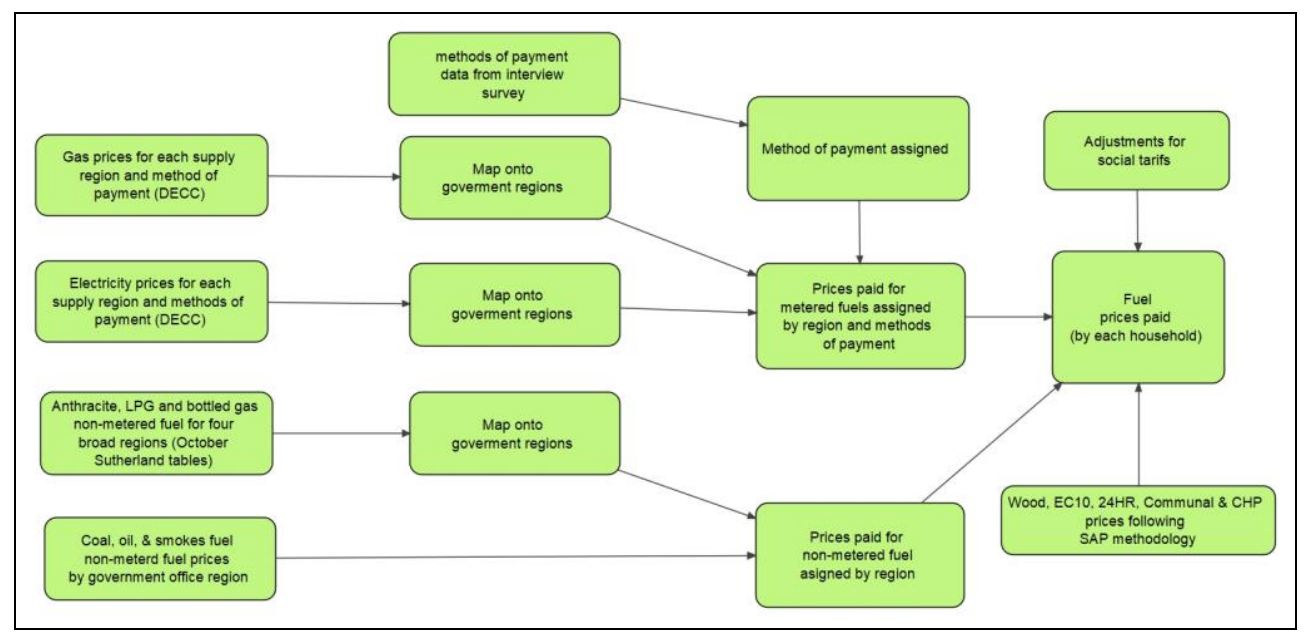

Fig. 2. Fuel price paid by each household

\section{Heating network framework}

Which models are most suited to support local energy planning in Newcastle, in particular the selection of appropriate energy system for (i) the disaggregation of total energy demand into relevant homogenous end-use categories, (ii) a systematic spatial analysis of social, economic and technological indicators for energy consumption and identification of the interrelationships, (iii) organization of determinants into a structure of spatial hierarchical levels of details (LOD) and units of analysis, (iv) formalization of the structure in mathematical relationships, (v) estimation of the energy base scenario at property level, building, communities, neighbourhoods and districts. (vi) design scenario for the energy efficiency measures and (vii) quantitative estimation using scenarios of areas experiencing improvements in fuel poverty.

To answer this question there is a need to consider the following issues (i) the future amount and type of energy demand, i.e. how is the annual energy consumption by use, level of detail (LOD) (dwelling, building, etc.) and by level of analysis (LOA) (micro, meso or macro), (ii) the relevant energy system supply that can meet the demanded forms of energy, (iii) the economic and environmental impacts of using the energy systems, (iv) how (according to which criteria) the energy systems should be deployed. The four issues mentioned above will be discussed in more detail below.

Most existing models in use in developing countries assess only technical aspects and financial and economic consequences of energy systems. A model has now also to include an environmental impact assessment, but not only those that can be expressed in quantitative terms. So far many qualitative social impacts that are basically of qualitative nature are ignored because impacts that cannot be quantified are excluded from the analysis.

However, these qualitative impacts may play a crucial role in the viability of an energy system. Therefore, this research will promote the use of impact models which have a multi-criteria approach, allowing for the inclusion of both quantitative (physical, monetary) as well as qualitative data. This way it is ensured that the energy systems' impacts can be assessed according to all possible preferences or criteria of the energy planners.

Since most existing impact models are integrated into the supply and/or demand models, they cannot be easily modified to include qualitative criteria. This is not the case with a modular scheme because each module can operate separately from the others. A modular approach is therefore preferred.

So the set of the model for local energy planning in Newcastle should consist of a modular package of models with exploring purposes and should at least include models for energy demand, energy supply, and impacts.

The inclusion of an appraisal model depends on whether the planner is the same person or group as the decision maker, but because of the modular build-up, an optional module for an appraisal is easily added. The approach will have to be bottom-up to allow for a detailed description of the energy forms needed to provide the energy services that end-users desire. The bottom-up approach is also necessary to enable a detailed description of the different supply technologies (conventional as well as renewable). The focus will be on those sectors that are the main consumers of energy.

As a final remark, the energy model in Newcastle can best be supported with a modular package of models. This package should include models for assessing energy demand, supply, and impacts at the local level. The purpose of these models must be exploring and the approach has to be bottom-up rather than top-down to allow for a detailed description of the energy services and the resulting demand for energy means, and the supply technologies [21].

\subsection{Combined Heat and Power (CHP)}

CHP is applicable in principle wherever there is a demand for heat (either for space \& water heating) at temperatures up to a maximum of around $450^{\circ} \mathrm{C}$. Natural gas is the most common fuel ( $67 \%$ of UK CHP fuel use). CHP ranges in size from a few kilowatts to hundreds of megawatts and can utilise a range of technologies and fuels; most common technologies are reciprocating engines (up to around 10 megawatts), open cycle gas turbines (up to around 50 megawatts) and combined cycle 
gas turbine plant (over 50 megawatts), but CHP technologies also include Fuel cells, Stirling cycle engines, Organic Rankine cycle, Steam turbines, etc. Economies depends on the ratio of heat to power demand on a site (surplus power can be exported but at a lower value) and duration of heat and power demand (4,500 hours per annum or more typically required). The energy savings correspond to energy cost savings for CHP users (15-40\% savings according to ADE).

UK government provides a number of incentives for CHP in view of its energy efficiency and carbon saving benefits, such as (i) $100 \%$ of capital investment in CHP can be offset against corporation tax liability in the year in which the investment was made; (ii) CHP is exempt from Climate Change Levy (CCL) costs on all fuel used and on any electrical output consumed on-site or supplied directly to known customers. CHP users, therefore, benefit from lower CCL costs than if they used gas boilers and grid electricity. (iii) CHP is exempt from Carbon Price Support costs in respect of emissions associated with generation for on-site consumption or for supply to neighbouring parties under a supply licence exemption. (iv) CHP plant and equipment are exempt from business rates; (v) Gas CHP, like other gas-fired power generating capacity, is eligible to participate in the Capacity Market; (vi) CHP users also avoid the various obligations and charges on retail electricity supply which suppliers recoup via retail electricity prices; and, (vii) CHP users can also generate value by participating in commercial electricity market services such as balancing services, STOR, or via reduced Triad fees.

The economic viability of natural gas-fired CHP is dependent on relative gas and electricity prices (in particular retail prices in the case of non-exporting CHP). However, DECC research identified a number of indicative non-financial barriers which may prevent costeffective CHP being deployed: (i) lack of senior champions for CHP within an organisation; (ii) lack of technical expertise and resource within public sector organisations and SMEs; (iii) disinclination to engage in the energy market (outside of core expertise, potentially limiting operational flexibility); (iv) lack of understanding of CHP and available benefits; (v) modelling and past deployment suggest gas CHP economics have been unfavourable in the recent past. There may therefore also be pre-conceptions about costeffectiveness to overcome.

Based on logic mapping, reviewing past measures and qualitative multi-criteria decision analysis DECC has identified the following measures as potentially effective at addressing these barriers (i) A government funded service to guide potential CHP developers through the process of assessing and developing a CHP project and accessing available financial benefits e.g. guidance on financial assessments, technical specifications, what benefits are available to a particular CHP scheme, risk management, how to participate in Capacity Market auctions etc. Probably delivered by a third party body contracted by government; (ii) Similar to the guidance offered by heat network delivery unit (HNDU) to Local Authorities developing heat networks or environment agency relationship managers.
UK government is providing part-funding for organisations to commission external CHP feasibility studies. Such studies would provide detailed advice on technical and economic feasibility in the organisation's specific circumstances and assist in developing a technical specification. Funding is likely to be competitively allocated, either by central government or via a third party body contracted by the government, similar to HNDU feasibility study funding to Local Authorities.

UK government or sector-led fora are exchanging best practice on assessing and developing CHP. Among these are (i) Physical or web-based meetings could be used to exchange case studies, information on recent changes in policy, best practice on accessing available support and to encourage participants to publicise more widely the benefits they are achieving from CHP operation; (ii) publication and maintenance of a portfolio of detailed best practice guides on CHP, assessing CHP opportunities, feasibility studies, financial assessment, procurement, operation and maintenance. Could be government funded with industry input via a steering group, or industry-led or alternatively more formal industry Codes of Practice or Standards might be appropriate on some subjects; (iii) Detailed case studies based on monitoring and evaluation of plant by a consultant (probably funded by government), over time a portfolio of case studies covering CHP in different sectors would provide a practical demonstration of the benefits being achieved by application of CHP and independent advice and recommendations on how to further optimise plant might act as an incentive to volunteer for a case study.

\subsection{Low carbon energy production - District Heating/Cooling}

The development of a low carbon district heating and cooling network is the largest single element identified within the Newcastle energy masterplan and is the project that is likely to have the greatest impact in delivering low carbon energy to the city. Based upon the work undertaken for the energy masterplan the council should consider a political and financial commitment to the promotion of a citywide district heating and cooling scheme.

Your Home Newcastle (YHN) is currently responsible for managing the heating and maintenance service to around 4,000 properties in total. There are four types of schemes as follows district heating, large group heating, small group heating, and sheltered heating schemes.

Newcastle City Council has two district heating schemes at present, one is a new installation at Riverside Dene and one at least twenty years old. There are also a number of small schemes which serve residential blocks of up to 40 units in one building. A new development of approximate 1800 dwellings is being delivered in the city and a district heating scheme will be installed to service this development. Newcastle City Council is a strong supporter of district heating with an aspiration to link the 
smaller heating schemes into a citywide ESCO in the future. All of the schemes are controlled by a computerised Building Management System located at the largest site in Byker. A small maintenance team uses this to monitor the temperatures and pressures of the systems to ensure they operate at the required design standards. The team is also responsible for carrying out planned maintenance and emergency repairs to the communal services within each scheme. Byker should be treated differently from the other schemes due to its size and complexity, and that a decision needs to be made as early as possible on the introducing metering as the key next step for Byker. Part of this consideration will be whether it is economically viable to carry out a pilot scheme at Byker, or if it is better to introduce a full solution on this estate to take advantage of the potential savings that could be made.

\section{Conclusions and further remarks}

YHN's community heating schemes vary in age, size, and design. Therefore it is important that a strategy for each scheme should be judged on its own merits. There should not be a 'one size fits all' strategy. However, as schemes are refurbished it is important that consideration is given to adequate controls, metering, alternative fuels, and technologies. In some of the smaller schemes, it may also be worth considering individual boilers.

All the options discussed are applicable to all schemes but because of the size and complexity of Byker any innovative ideas there should be run as a pilot first. There is an argument that it may be better to optimise and stabilise the system without changing it dramatically. However a range of more advanced technical options has been considered. Most of the reports previously commissioned have concerned the Byker scheme.

In all schemes, consideration should be given to isolating those homes belonging to leaseholders by separating them from the direct system via a heat exchanger. Thus giving them more control of their heating system.

Reducing dwelling heat demands is believed to be the key issue in reducing overall heat consumption. The available evidence overwhelmingly indicates that direct charging for heat use is essential if the potential reductions in demand are to be achieved. Therefore a programme to install heat meters in every residence and to implement an associated charging scheme should be planned as a priority irrespective of the changes made to the heating systems.

\section{References}

1. Newcastle City Council. Strategic Energy Action Plan (SEAP). 2007.

2. Newcastle City Council. Citywide Climate Change Strategy \& Action Plan 2010 - 20202010 [Available from:

http://www.newcastle.gov.uk/wwwfileroot/legacy/ns/ environment/DRAFTforPublicConsultationClimateC hangeStrategyActionPlanJune2010.pdf.
3. EST. Part L1 of the Building Regulations 2006 London: Briefing note; 2006.

4. Climate Change Act. Enacted: 26 November 2008, Chapter 27. London: TSO; 2008.

5. CCC. Meeting Carbon Budgets - 2014 Progress Report to Parliament. 2014.

6. Palmer J, Cooper I. United Kingdom housing energy fact file. In: Change DoEC, editor. 2013.

7. Palmer J, Terry N, Kane T. Early Findings: Demand side management. 2012.

8. HM Government. Definition of zero carbon homes and non-domestic buildings. London; 2008 December 2008. Report No.: Ref. No.: 08CCSD05675 Contract No.: ISBN: 978-1-4098-0934-0.

9. Department for Communities and Local Government. Building a Greener Future: policy statement. 2007.

10. Passivhaus Trust. Claiming the Passivhaus Standard: The UK context. 2011.

11. DCLG. Code for sustainable homes: Technical Guidance. London; 2010. Contract No.: ISBN 9781859463314.

12. HM Government. The Building Regulation 2000: Consevation of fuel and power - Approved document L1A: Conservation of fuel and power in new dwelling comming into effect 1 October 2010. London; 2010. Contract No.: ISBN 9781859463246.

13. HM Government. The Building Regulations 2010. Conservation of fuel and power L1B in existing dwellings. 2010.

14. HM Government. The Building Regulations 2010: Conservation of fuel and power - Approved document L1A: Conservation of fuel and power in new dwelling: 2013 edition - for use in England. London; 2013. Contract No.: ISBN 9781859465103.

15. HM Government. L1A Conservation of fuel and power in new buildings. 2013.

16. BRE. The Government's Standard Assessment Procedure for Energy Rating of Dwellings 2005 edition, revision 3. Garston, Watford; 2009.

17. SAP. Energy Performance Certificate. 2008.

18. Department for Communities and Local Government. Recast of the Energy Performance of Buildings Regulations. 2012.

19. BRE. BREEAM UK new construction. 2014.

20. European Commission. Application of EU law 2014 [Available from: http://ec.europa.eu/eu_law/introduction/what_directiv e_en.htm.

21. EPBD Directive. Directive 2010/31/EU of The European Parliament and of The Council of 19 May 2010 on the energy performance of buildings. In: Union E, editor. Official Journal of the European Union2010. p. L153:0013-33.

22. EPBD Directive. Directive 2012/27/EU of the European Parliament and of the Council of 25 October 2012 on energy efficiency, amending Directives 2009/125/EC and 2010/30/EU and 
repealing Directives 2004/8/EC and 2006/32/EC. In: Union E, editor. Official Journal of the European Union2012.

23. EPBD Directive. Directive 2009/28/EC of The European Parliament and of The Council of 23 April 2009 on the promotion of the use of energy from renewable sorces. In: Union E, editor. Official Journal of the European Union2009. p. L140:0016-62.

24. EPBD Directive. Directive 2009/72/EC of the European Parliament and of the Council of 13 July 2009 concerning common rules for the internal market in electricity and repealing Directive 2003/54/EC. In: Union E, editor. Official Journal of the European Union2009. p. L112:0055-93.

25. Department for Communities and Local Government. The Code for Sustainable Homes - Case Studies. 2012.

26. Department of Trade and Industry. Meeting the Energy Challenge A White Paper on Energy 2007.

27. HM Government. The UK Low Carbon Transition Plan. 2009.
28. Department of Trade and Industry. Our energy future - creating a low carbon economy. 2003.

29. HM Government. The Energy Challenge Energy Review Report 2006. In: Industry DoTa, editor. 2006.

30. UK Parliament. Energy Act 2008. London: TSO; 2008.

31. UK Parliament. Energy Act 2011. 2011.

32. DECC. Final Stage Impact Assessment for the Green Deal and Energy Company Obligation. 2012.

33. HM Treasury and HM Revenue \& Customs. Carbon price floor. 2010.

34. DECC. The Warm Home Discount Scheme. 2011.

35. Novak JD, Cañas AJ. The theory underlying Concept Maps and how to construct them. Florida Institute for Human and Machine Cognition; 2006.

36. Shapiro SC, Eckroth D. Encyclopedia of artificial intelligence: Wiley; 1987.

37. Sowa JF. Semantic Networks. Encyclopedia of Cognitive Science: John Wiley \& Sons, Ltd; 2006. 